\title{
A BRIEF STUDY ON RECYCLING OF WASTE PAPER
}

\author{
Jagram Meena ${ }^{1 *}$
}

${ }^{* 1}$ Department of Chemistry, SGTB Khalsa college, University of Delhi-110007

*Corresponding Author: -

\begin{abstract}
: -
Energy harvesting also known as power harvesting or energy scavenging is the process by which energy is derived from external sources solar power, thermal energy, wind energy, salinity gradients, and kinetic energy, captured, and stored for small, wireless autonomous devices, like those used in wearable electronics and wireless sensor.

Energy harvesters provide very small low-energy electronics. While the input fuel to some large-scale generation costs money (oil, coal, etc.), the energy source for energy harvesters is present as ambient background and is free. For example, temperature gradients exist from the operation of a combustion engine and in urban areas, there is a large amount of electromagnetic energy in the environment because of radio and television broadcasting
\end{abstract}

\section{(a) $(\$)$}




\section{INTRODUCTION}

At the time The Oregon Recycling Opportunity Act was passed, it set up a statewide system for managing solid waste that was called the most comprehensive in the nation. Residents of most cities over 4,000 population may place glass, tin, cardboard, newspaper, aluminum and motor oil at curbside for pickup. They and residents of the more rural areas of the state also may take recyclable materials to public landfills, transfer stations, and conveniently located drop-off centers. Whether Oregonians place recyclables at curbside or drop them off at a local collection depot, just where does the material go next? The specific route depends on the item in question, but there are some common threads. They have to do with words like collector and hauler, resale, transportation and energy. They have to do with conserving, and with saving natural resources and fossil fuels and materials. They have to do with insuring that we preserve our state as we know it for generations to come.

But the process of collecting and re-manufacturing recyclable materials, outlined here, is only part of recycling. Buying and using a recycled product completes the circle. Look for the recycled label on the products you buy, and ask your store manager to stock recycled products and products made of recycled material

\section{RECYCLING NEWSPAPER.}

You begin the recycling process when you set it apart from your household garbage and place it at curbside or in a bin at a drop-off depot. Or when you participate in a paper drive. Whichever method you select, the paper is picked up by recycling collector. At curbside, this might be your garbage hauler or a recycling service working with your garbage hauler. The collector combines your newspaper with paper from other households and sells them to a paper dealer who, because of the volume of material purchased, often operates out of a storage warehouse. The dealer then sells quantities of paper to a user. This is where the actual recycling--manufacturingone product into a new product--takes place.

Old newspaper is an essential material in the paper remanufacturing process. Because paper mills must be concerned about both quality (cleanliness, type of paper) and quantity of the supply, they usually issue purchasing contracts to dealers rather than buying small amounts of paper from the public. Some contracts might be for a month, while others are on.

Introduction the paper mill, de-inking facilities separate ink from the newspaper fibers through a chemical washing process. A slusher turns the old paper into pulp, and detergent dissolves and carries the ink away. Next, screens remove contaminants like bits of tape or dirt. The remaining pulp is bleached and mixed with additional pulp from wood chips to strengthen it. The watery mixture is poured onto a wire, a continuously moving belt screen which allows excess moisture to drain through. By the time the mixtures gets to the end of the belt, it's solid enough to be lifted off and fed through steam-heated rollers which further dry and flatten it into a continuous sheet of paper. This paper machine produces finished newsprint at the rate of 3,000 feet pe.

\section{ENERGY IN TRANSITION}

Energy can never be destroyed, as we know, without going through a chain of conversions between different forms. Some forms we value higher because they are easier to exploit and we can use for example the potential energy in a reservoir to drive turbines in a hydroelectric plant, and generators convert the motion into electrical energy that is easy to deploy and use for many different purposes. Electricity, for example, can drive an electric motor and be converted back into kinetic energy. From our perspective, the last link in many energy chains is to use low-grade heat, which usually is not utilized.

When we use energy there are always losses along the way in the chain - for example, the frictional heat in a machine or transformation losses in the electricity grid. The proportion of the added energy that makes use what we call efficiency: a gasoline-powered car can have an efficiency of around $25 \%$ and then uses a quarter of the fuel's energy to move itself and its cargo, and a muscle converts chemical energy into motion with similar efficiency.

From an environmental perspective, the energy issue is central and ever-present, and there are several ways to increase the environmental benefits by focusing on different stages of the chain. One way is of course to invest in cleaner forms of energy. Another is to switch to more energy-efficient appliances. A third is to choose technologies that minimize the losses in the distribution and transformation - and there are big gains to be made. Over a quarter of the energy produced is lost on the way to the us Energy Harvesting involves utilizing low-grade energy through to waste, mainly to power to recycle waste energy.

Yet another approach is something called energy harvesting. It involves various methods to take advantage of the ambient energy that is being wasted, and try to exploit it in the form of electricity. Waste energy can be small differences in heat, vibration, radio waves - or simply mechanical work from people in motion. The basic principle in energy harvesting is based on the piezoelectric, thermoelectric or pyroelectric effects of some materials.

Piezoelectric materials have the property of being able to extract electricity from movements, sounds and vibrations. The mechanism for this is that the materials have charges separated in a symmetric crystal structure; and when subjected to mechanical stress, a charge asymmetry arises that gives rise to voltage. 


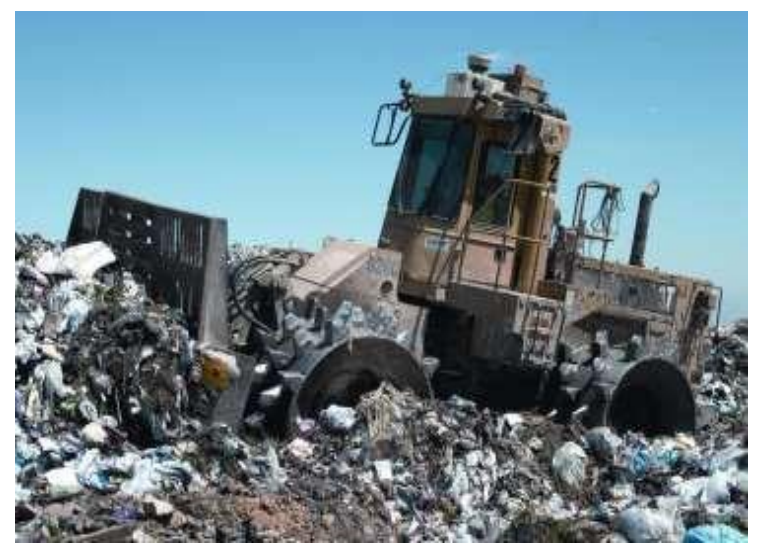

Thortical framework Thermoelectric and pyroelectric materials build an electric charge by absorbing and converting heat energy. In the former, it occurs when the crystals in the material experience a difference in temperature between its different sides. Pyroelectric materials generate electricity while the material undergoes a change in temperature.

\section{LOW POWER BUT GREAT POTENTIAL}

Since energy harvesting works with diffuse energies near the limit of what is meaningful to exploit, the effect is generally small. The primary use is therefore electronics with low power requirements - which, however, can be quite significant. One example is the network of wireless sensors - a technology that can bring great efficiencies in both industry and agriculture (see the article

"Effektiv are resursanvandning i jordbruket, or Efficient resource use in Agriculture"). In time, energy harvesting could go hand in hand with nanotechnology and allow self-guided micro-machines that are not limited by batteries. The possible applications of it would be almost unlimited, especially in biotechnology.

Another important area where energy harvesting can be useful is to replace batteries in medical implants, where the limited operating time otherwise poses a big problem. Heartbeat, internal organ motion or the body's glucose reserves can serve as sources of energy.

Energy harvesting has the potential to reduce the need for batteries in general. That in itself can be beneficial for the environment, for example, in view of the fact that some batteries contain toxic heavy metals.

Firms Pavegen and PowerLeap are examples of players who are experimenting with piezoelectric flooring and pavement coatings that can extract electricity from waste energy from those who go on them. Trial installations on a small scale are already being tested worldwide. Integrated in environments such as railway stations, and other places where large crowds are moving, they may provide significant contributions to the local electricity supply. A variation of this could be roads that pick up vibrations from the road surface to drive traffic signals. Other perhaps less revolutionary but still practical applications may be contributing to the power of mobile devices, thereby reducing the power draw from the grid.

Solar, wind and wave power in general can of course also be seen as energy harvesting, albeit on a larger scale and higher up in the energy chain. For example, wind turbines could also be constructed on a micro scale by using piezoelectric materials, to meet local needs. A proposed such design includes long, swaying stems of carbon fibre reinforced pipes as in Wind Talk project. The stems are made up of piezoelectric discs stacked on each other, which are deformed and build up when the wind blows.

Electronics with low power requirements. It provides an environmental benefit by doing more useful work with the energy we already produce. There are many applications where it is advantageous to not have batteries or wiring - everything from ground sensors to body implants. Innovations such as piezoelectric materials cultivated in the form of virus can help provide scalability to the technology.

curgently, most e-Waste is secretly burn to recover precious metals from chips etc.

Dioxins are produced if wires are coated with PVC. Substitutes are more expensive. We need plastic substrates that dissolve in Energy harvesting from waste heat.

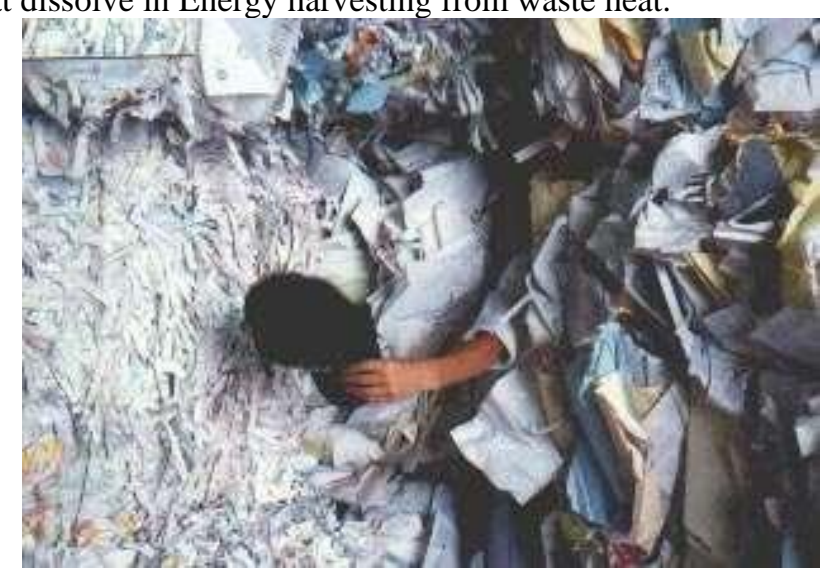




\section{MONITORING}

\section{Thermoelectric Materials}

We have developed deposition and fabrication capabilities for structured BiTe (Bismuth Telluride) films and scalable devices, and demonstrated energy conversion from heat to a measurable voltage proportional to the temperature. Our technology provides an advantage over conventional bulk structures, being based on thin films on low thermal conductivity substrates. A conventional BiTe semiconductor thermoelectric device is typically $5 \mathrm{~mm}$ thick. Our approach, shown below, is based on thin films of the same BiTe materials but only 150 microns in thickness. We are now in the process of testing thinner lower conductivity ceramic substrates as an alternative to the glass which is currently used, including flexible substrates. Our approach will allow individual devices to be stacked, enabling a much larger set to be created in series or parallel and significantly increasing efficiency. Alongside our BiTe device work, we are also now evaluating new materials for thermoelectric power generation, in particular improving efficiency through increasing the temperature range at which these devices can be operate.

\section{FINDING:-}

\section{Waste Data Tables}

The waste data tables present the data from each of the above tools in Excel format. The waste is shown in a summary and by detailed waste types. The Waste from households: waste data tables 2013 is taken from the household tool, and the Waste from all sources: waste data tables 2012 is taken from the waste from all sources tool.

\begin{tabular}{|c|c|c|}
\hline Publications & Reporting year & Format \\
\hline Waste from households: waste data tables 2013 & 2013 & 임 $(2.3 \mathrm{mb})$ \\
\hline Waste from all sources: waste data tables 2012 & 2012 & 임 $(2.3 \mathrm{mb})$ \\
\hline Waste data quality report 2012 & 2012 & 흐 $(337 \mathrm{~kb})$ \\
\hline Waste data tables 2011 & 2011 & (868k) \\
\hline Waste data quality report 2011 & 2011 & 흐 $(745 \mathrm{~kb})$ \\
\hline
\end{tabular}

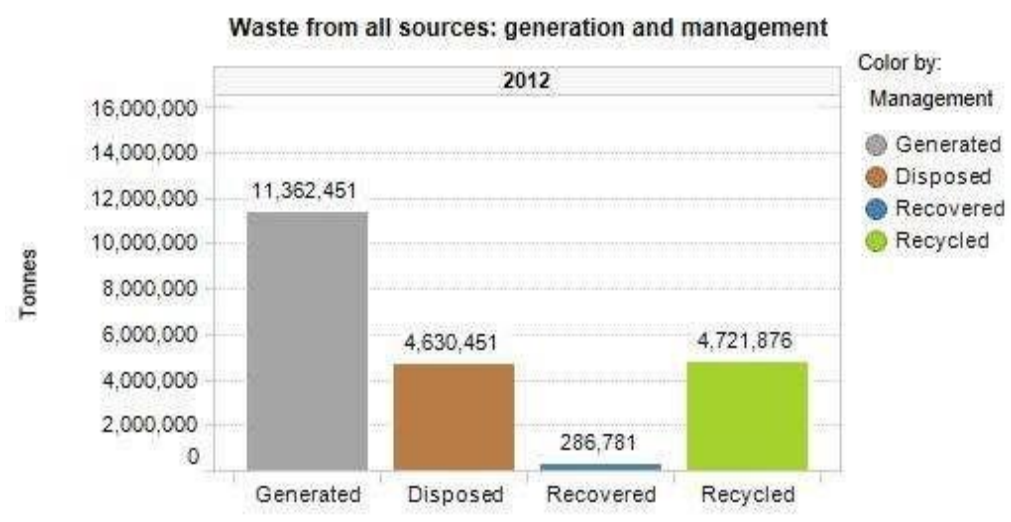

The waste from households waste data tables 2014 will be available in September

Waste Reduction and Recycling 10,000 9,000 (ton) (\%)

Waste volume FY97 FY98 FY99 FY00 8,000 6,000 4,000 2,000 7,000 200150100

502505,000 3,000 1,000 00 Trend in Waste Volume Basic unit Basic unit $=-($ FY1997 $=100 \%)$

Breakdown of TEL Group's FY2000 Waste Volume Other $8.3 \%$ Glass, beverage containers, packaging materials, incinerated ash 3.0\% Liquid waste 30.1\% Specially controlled liquid waste $17.7 \%$ Cafeteria garbage $1.3 \%$ Scrap wood 3.8\% Scrap metal/ product 12.2\% Plastic 5.0\% Paper 14.5\% Breakdown of FY2000 Waste Volume by Location Miyagi 2.9\% Koshi 3.0\% Fuchu 5.0\% Ozu 3.2\% Yokohama 4.0\% Sagami 5.7\% Tohoku 8.5\% Fujii 11.9\% Kumamoto 16.3\% Saga 14.3\% Hosaka 25.3\% 8,072.4 6,347.1 7,109.3 9,267.6 Waste volume Sales Total waste volume 9,267.6 t

Waste reduction is an important issue in terms of both preserving the global environment and alleviating the burden on incinerators and other waste disposal facilities. Our philosophy is, "Minimize waste generation, maximize recycling of wastes that are generated, and properly dispose of wastes that cannot be recycled." In accordance with this philosophy, every TEL Group plant reduces the amount of waste it generates and sorts wastes to facilitate recycling. I Total Waste Volume The bar graph at right shows the progression of the TEL Group's total waste volume, on a year-to-year basis. The linear graph shows changes in the basic units, calculated by dividing waste volume by sales of each year. For the purpose of comparing yearly results, the basic units (used to show the relationship between sales and waste volume) are calculated by taking the result of fiscal year 1997 as 100 points (100\%). In fiscal year 1999, we started keeping a tally of the amount of waste generated by our non-manufacturing facilities, in addition to those at our manufacturing plants. In fiscal year 2000, waste volume at manufacturing plants and research facilities grew in tandem with the substantial rise in production volume and utilization of plant capacity. 
As a result, the TEL Group's total waste volume increased compared to that in fiscal year 1999. However, the basic unit improved considerably, from 121.4 points in fiscal year 1999 to 72.2 points in fiscal year 2000. This is equivalent to a drop of over 40 percent, or, $59.5 \%$ decrease.

The Water Environment (Oil Storage) (Scotland) Regulations 2006 came into force on the 1st April 2006. They apply to the storage of any kind of oil including petrol, diesel, waste vegetable and plant oil and biodiesel and apply to any kind of container which is being used and which is stored on premises above ground, whether inside or outside a building. The range of premises covered by the Regulations is wide including land and mobile plant but does not include storage of oil in vehicles or vessels. The regulations lay down requirements for the design and construction of oil storage containers with a capacity of more than 200 litres (the average 44 gallon drum): the container must be of sufficient strength and structural integrity so as to ensure that it is unlikely to burst or leak in its ordinary use. Where the container has a storage capacity of 200 litres or more the regulations require provision of secondary containment (a 'bund' or 'drip-tray')

\section{CONCLUSION: -}

The increasing human population the needs for the people also increases. But the point of concern is that are there enough natural resources to service all your needs. What if these resources finish, this is one thing we need to ponder upon. We need to start recycling waste to converse our natural resources. Recycling is simply the process of reusing the items from which utility can still be derived. It is important to recycle waste so that you can at least converse some of our natural resources for our generations to come.

Many products such as paper, cardboards, and cups come from trees. In fact trees are our natural assets, you can converse trees by recycling the paper products we can minimize the number of trees cut down a year. This is one form of waste recycling.

One should understand and know the importance of recycling waste materials. One simple benefit of recycling is it saves our resources.

It will be wise to reuse metal item as metal reserves may be depleting. You can sold your wore out metal items for recycling. As mentioned earlier, recycling of waste papers can save our forests.

\section{SUGGESTIONS: -}

Recycling waste not only save our natural resources but also help save energy. By simply recycling an item or making a basic fix to it, we can we save all the energy that would have been consumed in the process of making it. The same example can be taken with plastic items. A large amount of energy can be saved by simply reusing the plastic items. To recycle waste is to simply reduce pollution.

By recycling plastic material we can reduce air pollution as well as water pollution. Plastic factories produced large amount of smoke when producing plastic material at the same time if we don't have proper waste disposal system those waste emissions will cause water pollution. Recycling waste in a way helps reduce pollution.

\section{REFERENCE: -}

[1].International Resource Panel,United Nations Environment Programme

[2]."How Urban Mining Works". Retrieved August 9, 2013.

[3].N.C. McDonald and J. M. Peace, "Producer Responsibility and Recycling Solar Photovoltaic Modules", Energy Policy 38, pp. 7041-7047(2010). Open access available

[4]."London 2012 seeks sustainable solutions for temporary venues". ODA.Retrieved August 20, 2012.

[5].http://www.calrecycle.ca.gov/homehazwaste/Events/AnnualConf/2006/Ap ril27/Session4/CompRecTH.pdf.

[6].Jp (2009-04-22). ""Eco"-plastic: recycled plastic".

[7]."RESEM A Leading Pyrolysis Plant Manufacturer". RESEM Hydrolysis Plant. Retrieved

[8].Plastic Recycling codes, American Chemistry

[9].About resin identification codes American Chemistry

[10]. "Recycling Symbols on Plastics - What Do Recycling Codes on Plastics Mean". The Daily Green. Retrieved February 29, 2012.

[11]. Unless otherwise indicated, this data is taken from The League of Women Voters (1993). The Garbage Primer. New York: Lyons \& Bur ford. pp. 35-72. ISBN 1-55821-250-7., which attributes, "Garbage Solutions: A Public Officials Guide to Recycling and Alternative Solid Waste Management Technologies, as cited in Energy Savings from Recycling,January/February 1989; and World-watch 76 Mining Urban Wastes: The Potential for Recycling, April 1987."

[12]. "Recycling metals — aluminium and steel". Retrieved November 1, 2007.

[13]. "Recycling Benefits to the Economy". WWW.all-recycling-facts.com. Retrieved February 1, 2013.

[14]. "A Recycling Revolution". www.recycling-revolution.com Retrieved February 1, 2013.

[15]. Laved D. (2007). Is Municipal Solid Waste Recycling Economically Efficient? Environmental Management.

[16]. Vigso, Doter (2004). "Deposits on single use containers - a social cost-benefit analysis of the Danish deposit system for single use drink containers". Waste Management \& Research 22 (6): 477-87.

[17]. "Minerals and Forensic Science" (PDF). University of Massachusetts Lowell, Department of Environmental, Earth, \& Atmospheric Sciences.

[18]. "Phosphorus Famine: The Threat to Our Food Supply". Scientific American. June 2009

[19]. "Peak Everything?". Reason Magazine. April 27, 2010. 
[20]. "Much toxic computer waste lands in Third World". Saturday.com. 2002-02-25. Retrieved November 6, 2012.

[21]. "Environmental and health damage in China". Web.archive.org. 2003-11-09. Archived from the original on 200311-09. Retrieved November 6, 2012.

[22]. "Illegal dumping and damage to health and environment". Retrieved November 6,2012.

[23]. Hog M. Waste outshines gold as prices surge. Financial Times.(registration required)

[24]. Bonnie Desiccant. (2006). Rewarding Recyclers, and Finding Gold in the Garbage 